\title{
Adenyl Cyclase and Interleukin 6 Are Downstream Effectors of Parathyroid Hormone Resulting in Stimulation of Bone Resorption
}

\author{
Edward M. Greenfield, Steven M. Shaw, Sandra A. Gornik, and Michael A. Banks \\ Department of Orthopaedics and Department of Pathology, Case Western Reserve University, Cleveland, Ohio $44106-5000$
}

\begin{abstract}
Parathyroid hormone and other bone resorptive agents function, at least in part, by inducing osteoblasts to secrete cytokines that stimulate both differentiation and resorptive activity of osteoclasts. We previously identified two potentially important cytokines by demonstrating that parathyroid hormone induces expression by osteoblasts of IL-6 and leukemia inhibitory factor without affecting levels of 14 other cytokines. Although parathyroid hormone activates multiple signal transduction pathways, induction of IL-6 and leukemia inhibitory factor is dependent on activation of adenyl cyclase. This study demonstrates that adenyl cyclase is also required for stimulation of osteoclast activity in cultures containing osteoclasts from rat long bones and UMR106-01 rat osteoblast-like osteosarcoma cells. Since the stimulation by parathyroid hormone of both cytokine production and bone resorption depends on the same signal transduction pathway, we hypothesized that IL-6 might be a downstream effector of parathyroid hormone. We found that addition of exogenous IL-6 mimics the ability of parathyroid hormone to stimulate bone resorption. More importantly, an antibody directed against the IL-6 receptor blocks moderate stimulation of osteoclast activity induced by the hormone. Interestingly, strong stimulation of resorption overcomes this dependence on IL-6. Thus, parathyroid hormone likely induces multiple, redundant cytokines that can overcome the IL-6 requirement associated with moderate stimulation. Taken together with studies showing that many other bone resorptive agents also stimulate IL-6 production, our results suggest that IL-6 may be a downstream effector of these agents as well as of parathyroid hormone. (J. Clin. Invest. 1995. 96:1238-1244.) Key words: osteoblast
\end{abstract}

Portions of this work have been presented in preliminary form at annual meetings of the American Geriatrics Society in New Orleans, LA on 15-19 November 1993, the American Society for Bone and Mineral Research in Tampa, FL on 18-22 September 1993 and in Kansas City, MO on 9-13 September 1994, the American Society for Cell Biology in New Orleans, LA on 11-15 December 1993, the Arthritis Foundation in Phoenix, AZ on 18-20 June 1993, and the Orthopaedic Research Society in Washington, DC on 17-20 February 1992 and in San Francisco, CA on 15-18 February 1993.

Address correspondence to Edward M. Greenfield, Ph.D., Department of Orthopaedics, Case Western Reserve University, 11100 Euclid Avenue, Cleveland, OH 44106-5000. Phone: 216-368-1331; FAX: 216368-1332.

Received for publication 30 January 1995 and accepted in revised form 23 May 1995.

J. Clin. Invest.

(C) The American Society for Clinical Investigation, Inc.

0021-9738/95/09/1238/07 \$2.00

Volume 96, September 1995, 1238-1244
- osteoclast • cytokine $\cdot$ cell-cell interactions $\cdot$ bone resorption

\section{Introduction}

Net bone loss, in conditions such as osteoporosis, results from a disturbance in the normal balance between bone resorption by osteoclasts and bone formation by osteoblasts. Thus, knowledge of the mechanisms that regulate both resorption and formation of bone is fundamental to the understanding of the pathogenesis of these diseases.

In addition to forming bone, osteoblasts regulate osteoclast resorptive activity in response to parathyroid hormone (PTH) and other resorptive agents $(1,2)$. This concept is best supported by evidence that many agents, including PTH, only stimulate osteoclast resorptive activity in the presence of osteoblasts or conditioned media from osteoblasts that had been exposed to PTH $(3,4)$. The primary effect of PTH is therefore believed to be stimulation of production by osteoblasts of soluble cytokines that, in turn, function as downstream effectors to activate osteoclasts. However, the identity and functions of these critical cytokines are unknown.

To identify osteoblast-derived cytokines that may be important in stimulation of bone resorption, we previously examined the effect of PTH on expression by osteoblasts of 16 different cytokine genes (5). The only mRNAs that were responsive to PTH were those encoding interleukin 6 (IL-6) and leukemia inhibitory factor (LIF), ${ }^{1}$ which were rapidly and transiently stimulated. Maximal stimulation was $\sim 10-50$-fold. We and others have also found that secretion of both IL-6 and LIF proteins is stimulated by PTH (5-11) as well as by many other resorptive agents, including $\mathrm{PTH}-$ related protein, $\mathrm{IL}-1$, tumor necrosis factor, 1,25-dihydroxyvitamin $D_{3}$, transforming growth factor- $\beta$, vasoactive intestinal peptide, isoproterenol, and lipopolysaccharide $(5,6,8-10,12-16) .^{2}$ Demonstration that PTH and other resorptive agents induce IL- 6 production by osteoblasts in conjunction with reports that IL-6 stimulates bone resorption $(7,9,12)$ suggests that osteoblast-derived IL-6 might be a common downstream effector of many bone resorptive agents (5). Although in particular cell preparations PTH does not stimulate IL-6 production $(9,10,12)$ and IL- 6 does not induce resorption (17-19), these discrepancies are likely due to investigation of cells at different developmental stages or lack of adequate assay sensitivity (for review see reference 5). The importance of IL- 6 is underscored by recent findings that implicate this cytokine in the increased bone resorption that occurs during estrogen withdrawal $(2,14,20,21)$, in Paget's

1. Abbreviations used in this paper: LIF, leukemia inhibitory factor; TRAP, tartrate-resistant acid phosphatase.

2. Greenfield, E. M., M. C. Horowitz, and S. A. Gornik, manuscript submitted for publication. 
disease $(22,23)$, in Gorham-Stout disease (24), and in some forms of hypercalcemia of malignancy (25).

PTH activates both the classical adenyl cyclase signal transduction pathway as well as the phospholipase $\mathrm{C}$ pathway through binding to a single receptor (26). Pharmacological activation of either pathway can stimulate bone resorption (2729). To fully understand the mechanism by which PTH stimulates bone resorption, it is therefore important to clarify which pathway (s) is involved in this process. PTH-(3-34), a partial agonist that activates phospholipase $\mathrm{C}$ but not adenyl cyclase, has proven useful to determine whether adenyl cyclase is involved in a particular response $(30,31)$. Previously, we used PTH-(3-34) to demonstrate that adenyl cyclase activation is required for induction of IL-6 mRNA and protein in osteoblasts by PTH. ${ }^{2}$ In this study, we demonstrate that activation of adenyl cyclase is also required for stimulation of bone resorption. These results led us to examine whether IL-6 is one of the crucial cytokines produced by osteoblasts to stimulate osteoclast resorptive activity. We show that addition of exogenous IL- 6 can mimic the effect of PTH on bone resorption and that moderate stimulation by PTH requires IL-6 production. Interestingly, this dependence on IL- 6 can be overcome by strong stimulation of osteoclast activity by PTH.

\section{Methods}

PTH-(1-34) and PTH-(3-34) were obtained from Bachem California (Torrance, CA); and recombinant murine IL-6 was from Genzyme Corp. (Boston, MA). All of these agents were screened for endotoxin contamination using the colorimetric Limulus amebocyte lysate assay (No. QCL-1000; Whittaker M. A. Bioproducts, Walkersville, MD). For the hormones, endotoxin levels were $<0.0008 \mathrm{Eu} / \mathrm{ml}$ for the highest concentration used in the experiments and were $<0.1 \mathrm{Eu} / \mathrm{ml}$ for the highest concentration of IL- 6 used. Moreover, none of these agents revealed significant endotoxin contamination in our previously described (5) functional assay examining cytokine expression in osteoblastic MC3T3-E1 cells (see Fig. 2). Cytokine mRNA levels were assessed by reverse transcription-PCR as described previously (5) except that the actin primers were those described in reference 32. All of the PCR primer pairs were selected so as to amplify mRNA regions that flanked at least one intron to allow discrimination between amplification of cDNA and genomic DNA. Controls without cDNA and with known positive cDNAs were used in all PCR reactions. To confirm the identity of the PCR products, we showed that fragments of appropriate sizes were produced by diagnostic restriction enzymes (5).

UMR106-01 rat osteoblast-like osteosarcoma cells (33) were kindly provided by Dr. N. Partridge (St. Louis University, St. Louis, MO). UMR106-01 cells between passages 18 and 24 were harvested using 0.02\% EDTA (Sigma Immunochemicals, St. Louis, MO) and plated at $25,000 \mathrm{cells} / \mathrm{cm}^{2}$ in phenol red-free (34) minimum essential medium (GIBCO BRL, Gaithersburg, MD) containing nonessential amino acids (Mediatech, Inc., Herndon, VA), 2 mM L-glutamine (Mediatech, Inc.), $10 \%$ fetal bovine serum (Hyclone Laboratories, Logan, UT), $100 \mathrm{U} / \mathrm{ml}$ penicillin (Mediatech, Inc.), and $100 \mu \mathrm{g} / \mathrm{ml}$ streptomycin (Mediatech, Inc.). All media, serum, and additives were from lots that contained the lowest concentration of endotoxin available. Spent media from UMR106-01 cultures were consistently negative when assayed for mycoplasma contamination by solution hybridization to a probe complementary to mycoplasma rRNA (Gen-Probe, San Diego, CA).

Bone resorption was measured in osteoblast/osteoclast cocultures established by a modification of previously described methods $(3,4)$. Briefly, long bones from 3-d-old Sprague-Dawley rat pups (4-6 pups/ preparation) were minced and then triturated in the cell culture media described above buffered with $20 \mathrm{mM}$ Hepes ( $\mathrm{pH}$ 7.2). After allowing

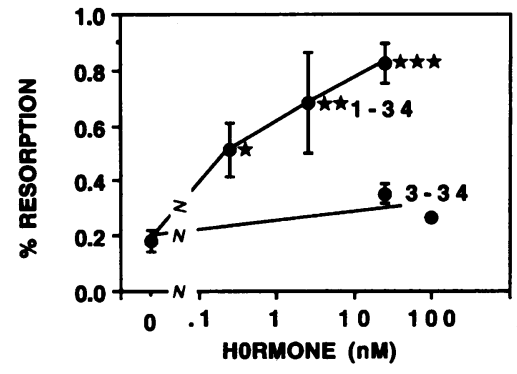

Figure 1. PTH-(3-34) is unable to mimic the ability of PTH-(1-34) to stimulate resorption. Osteoblast/osteoclast cocultures were treated with the indicated concentrations of PTH-(134), PTH-(3-34), or acetic acid vehicle (final concentration $=10 \mu \mathrm{M}$ )

for $24 \mathrm{~h}$. Data are presented as the area resorbed (percentage of the total bone slice area $) \pm \operatorname{SEM}(n=4) .{ }^{*} P=0.043,{ }^{*} P=0.004,{ }^{* * *} P$ $=0.0005$.

debris to settle out, the cell suspension was transferred to a 35-mm Petri dish containing 30 slices $(3 \mathrm{~mm} \times 3 \mathrm{~mm} \times 0.2 \mathrm{~mm})$ of bovine cortical bone or sperm whale dentin (kindly provided by Dr. C. Potter, National Museum of Natural History, Washington, DC). After incubation for 15 $\min \left(5 \% \mathrm{CO}_{2}, 37^{\circ} \mathrm{C}\right)$, bone slices were rinsed in PBS and transferred in groups to wells $\left(2 \mathrm{~cm}^{2}\right)$ containing preincubated media (lacking Hepes). UMR106-01 cells were added at a density of 50,000/well to ensure PTH responsiveness. After $2 \mathrm{~h}\left(5 \% \mathrm{CO}_{2}, 37^{\circ} \mathrm{C}\right)$, potential resorptive agents were added and the cultures (total volume $=0.4 \mathrm{ml}$ ) were incubated for another $24 \mathrm{~h}$. Bone and dentin slices were sonicated in Triton X-100, rinsed in PBS, fixed in glutaraldehyde, dehydrated in ethanol, and stained with toluidine blue as described (35). Resorption lacunae were measured in blinded fashion by computer-assisted histomorphometry (Bioquant System IV; R\&M Biometrics, Inc., Nashville, TN). Total resorbed areas are reported as a percentage of the total surface area of the slice \pm SEM. Experiments were excluded from further analysis if stimulated cultures exhibited SEM $>20 \%$ of the mean. All reported data are representative of multiple experiments, with the exception of Fig. 5 which is a compendium of six experiments.

Osteoclast number was determined in some experiments by staining the bone or dentin slices for tartrate-resistant acid phosphatase (TRAP) using a commercial kit (No. 387-A; Sigma Immunochemicals), but increasing the tartrate concentration to $50 \mathrm{mM}$. After counting the TRAP-positive, multinucleated cells, slices were sonicated, fixed, and stained with toluidine blue as described above. Results are reported as number of osteoclasts counted per dentin slice \pm SEM.

In experiments comparing multiple treatments to a control (see Figs. 1 and 2), statistical analysis was by ANOVA with a Bonferroni/Dunn post-hoc test performed on SuperANOVA software (Abacus Concepts, Inc., Berkeley, CA). In experiments comparing two means (see Figs. 4-6), statistical analysis was by Student's $t$ test.

\section{Results}

Stimulation of resorption by PTH involves activation of adenyl cyclase. To determine whether activation of adenyl cyclase is required for stimulation of resorption by $\mathrm{PTH}$, we compared the effects of fully active PTH-(1-34) and PTH-(3-34), a partial agonist that activates phospholipase $\mathrm{C}$ but not adenyl cyclase (31). As expected, 0.25-25 nM PTH-(1-34) dosedependently stimulates resorption in cultures containing osteoclasts from rat long bone as well as UMR106-01 rat osteoblastlike osteosarcoma cells (Fig. 1). In contrast, PTH-(3-34) has little, if any, effect on bone resorption even at concentrations as high as $100 \mathrm{nM}$ (Fig. 1). These results demonstrate that the adenyl cyclase signal transduction pathway is required for stimulation of resorption by PTH.

IL-6 stimulates bone resorption. Because IL- 6 production in response to PTH also depends on adenyl cyclase activation, ${ }^{2}$ 


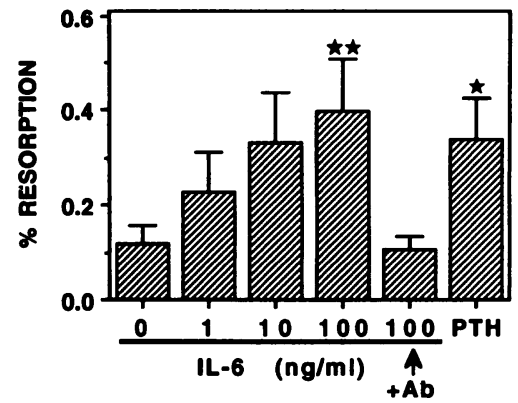

Figure 2. IL-6 stimulates bone resorption. Osteoblast/osteoclast cocultures were preincubated for $2 \mathrm{~h}$ with the anti-IL6 receptor antibody or nonimmune rat IgG before addition of the indicated concentrations of IL-6, PBS vehicle, or 25 nM PTH-(1-34). Data are presented as the area resorbed (percentage of the total bone slice area) \pm SEM $(n=4-5)$. $* P=0.088, * * P=0.047$.

we examined whether IL-6 is involved in stimulation of resorption by PTH. As a first step toward this goal, we studied the ability of IL-6 to mimic the effect of PTH on bone resorption. IL-6 dose-dependently stimulates resorption to an extent comparable with that induced by PTH (Fig. 2). This IL-6-induced resorption is not due to endotoxin contamination of the IL-6 preparation, as such contamination was not detectable by either the Limulus amebocyte lysate assay or our previously described (5) functional assay assessing cytokine expression by MC3T3E1 osteoblasts. In particular, unlike endotoxin, IL-6 does not stimulate IL- $1 \alpha$, tumor necrosis factor- $\alpha$, or granulocyte monocyte-colony stimulating factor mRNA levels in these cells (Fig. 3 ). However, IL-6 does increase expression of mRNAs encod-

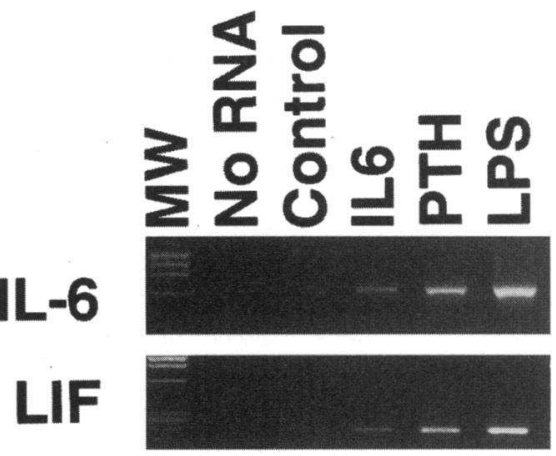

IL1 $\alpha$

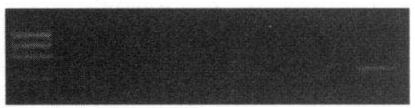

TNF $\alpha$

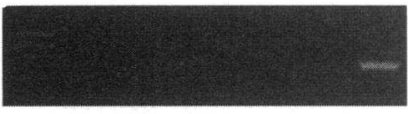

GMCSF

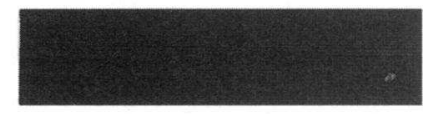

ACTIN

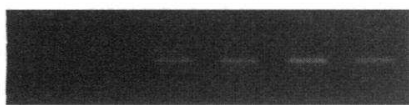

Figure 3. IL-6 stimulates expression of mRNAs encoding IL-6 and LIF, without affecting those encoding IL- $1 \alpha$, tumor necrosis factor- $\alpha$, granulocyte-monocyte colony stimulating factor, or actin. In contrast, lipopolysaccharide stimulates expression of all five cytokines. MC3T3-E1

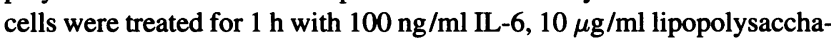
ride, or $1 \%$ PBS as a negative control. mRNA levels were assessed by reverse transcription-PCR.

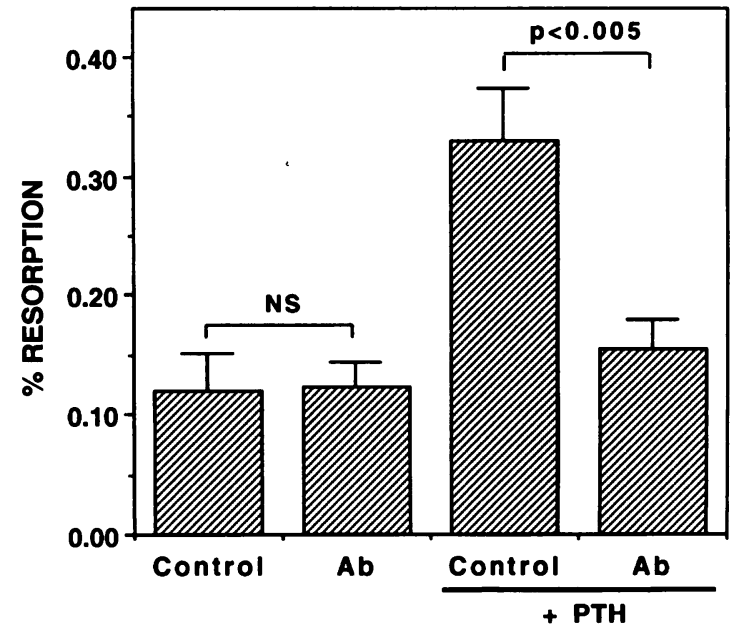

Figure 4. Anti-IL-6 receptor antibody can inhibit the effect of PTH on bone resorption. Osteoblast/osteoclast cocultures were preincubated for $2 \mathrm{~h}$ with $100 \mu \mathrm{g} / \mathrm{ml}$ of anti-IL-6 receptor antibody (No. 1922-01; Genzyme Corp.) or nonimmune IgG (Sigma Immunochemicals) before addition of PTH-(1-34) or acetic acid. Data are presented as the area resorbed (percentage of the total bone slice area) \pm SEM $(n=7) . N S$, not significant.

ing itself and LIF (Fig. 3). Moreover, the ability of IL-6 to stimulate bone resorption was inhibited by a neutralizing monoclonal antibody directed against the IL-6 receptor (Genzyme Corp.) (Fig. 2). In this experiment, as well as those depicted in Figs. 4 and 5, cultures treated with the IL-6 receptor antibody were always compared with cultures treated with nonimmune IgG. In addition, we confirmed that addition of nonimmune IgG has no effect on basal resorption or that stimulated by IL-6 or PTH (data not shown).

An anti-IL-6 receptor antibody can block stimulation of bone resorption by PTH. To directly assess whether IL- 6 is involved in stimulation of resorption by PTH, we measured the effect of adding the neutralizing antibody directed against the IL-6 receptor. Fig. 4 demonstrates that the antibody can block the ability of PTH to stimulate resorption without affecting basal resorption.

We and others $(4,36)$ have observed that the stimulation

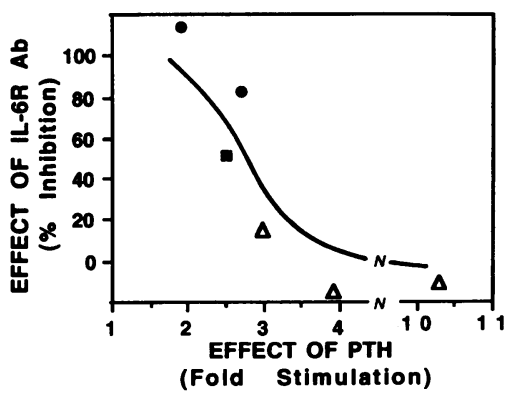

Figure 5. High-level (greater than or equal to threefold) stimulation of resorption by PTH overcomes dependence on IL-6. Osteoblast/osteoclast cocultures were preincubated for $2 \mathrm{~h}$ with the anti-IL-6 receptor antibody (No. 1922-01, Genzyme, Cambridge, MA) or nonimmune IgG

(Sigma, St. Louis, MO) before addition of $25 \mathrm{nM}$ PTH-(1-34) or acetic acid. Fold PTH stimulation was calculated using the formula: (resorption with PTH)/(resorption with vehicle). Per cent blockage of PTH effect by anti-IL-6 receptor antibody was calculated using the formula: 100 $\times\{1-[($ resorption with antibody and PTH $)-($ resorption with vehicle) $] /[$ (resorption with PTH) - (resorption with vehicle) $]\}$. Filled circles, $P<0.025$; filled square, $P<0.1$; open triangles, not significant. 

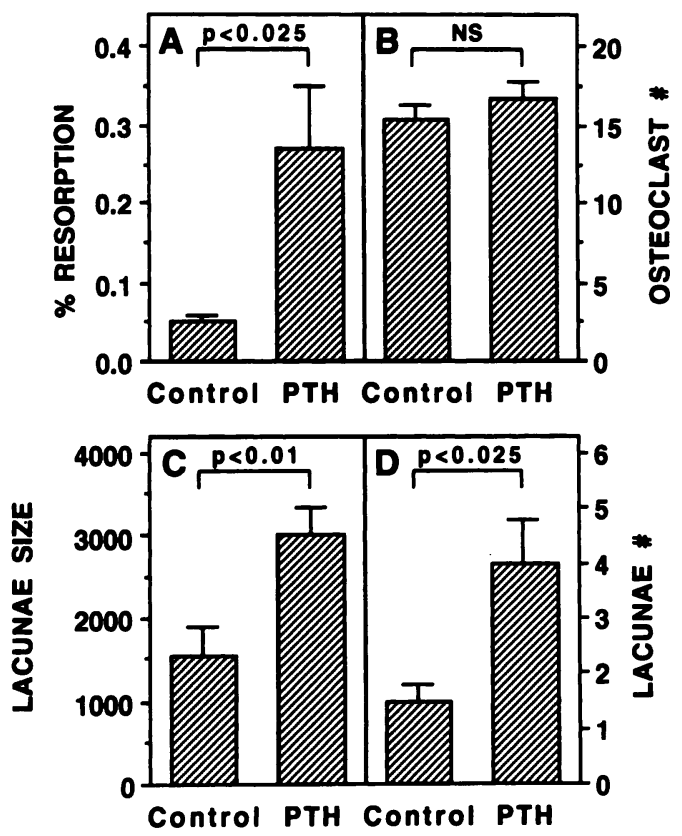

Figure 6. PTH stimulates bone resorption primarily by increasing osteoclast activity rather than osteoclast differentiation in short-term osteoblast/osteoclast cocultures. Osteoblast/osteoclast cocultures were treated with $25 \mathrm{nM}$ PTH-(1-34) or acetic acid vehicle for $24 \mathrm{~h}$. Dentin slices were stained for TRAP and the osteoclasts were counted. After counting, cells were removed, dentin slices were stained with toluidine blue, and the extent of resorption was determined. $A$ shows the area resorbed (percentage of the total slice area) $\pm \operatorname{SEM}(n=4-5) . B$ shows the number of osteoclasts per dentin slice $\pm \operatorname{SEM}(n=4-5)$. $C$ shows the size $\left(\mu \mathrm{m}^{2}\right)$ of individual resorption lacunae \pm SEM $(n=6$ for control and $n=20$ for PTH-treated). $D$ shows the number of resorption lacunae per dentin slice \pm SEM $(n=4-5)$. NS, not significant.

of bone by PTH varies between 2- and 10-fold from experiment to experiment. This variation presumably reflects different numbers of osteoblasts and/or osteoclasts in the cell preparations. We therefore hypothesized that the requirement for IL-6 might vary in experiments with different levels of stimulation. Accordingly, we examined the effect of the IL- 6 receptor antibody in experiments with various levels of stimulation by PTH. Fig. 5 shows that the dependence on IL-6 is only seen in experiments where PTH has a moderate stimulatory effect on resorption (two- to threefold) and is overcome when PTH strongly induces resorption (greater than or equal to threefold).

Stimulation of bone resorption in this study likely reflects osteoclast activation rather than osteoclast differentiation. IL6 has previously been thought to stimulate bone resorption primarily by inducing osteoclast differentiation rather than by directly stimulating osteoclast activity $(2,7,37)$. This concept reflects the ability of IL-6 to induce formation of TRAP-positive, multinucleated cells from mononuclear precursor cells $(38-40)$. In contrast to those studies that involve culture periods of 1-3 wk, our experiments were restricted to $24 \mathrm{~h}$. Thus, stimulation of resorption in our study would be expected to primarily reflect osteoclast activation. However, to assess the possibility that a limited amount of osteoclast differentiation might occur during our 24-h cultures, we quantitated the number of TRAP-positive, multinucleated cells on the bone slices after culture in the presence or absence of PTH. Since PTH potently stimulates resorption (Fig. $6 \mathrm{~A}$ ) without affecting the number of such osteoclasts in these cultures (Fig. $6 \mathrm{~B}$ ), the stimulation of resorption induced by PTH or IL-6 likely reflects osteoclast activation rather than osteoclast differentiation. Another potential method for assessing whether stimulation of resorption reflects activation or differentiation is to determine the relative contribution of increases in size and number of the resorption lacunae formed. Increases in lacunae size must reflect osteoclast activation while increases in number of lacunae can reflect osteoclast differentiation, activation of previously inactive osteoclasts, and/or increased osteoclast activity such that each osteoclast produces more lacunae. Fig. 6 shows that PTH increases both lacunae size (1.9-fold) and number (2.7-fold). Thus, increased lacunae size represents $35 \%$ of the total PTH effect $(1.9-1 /[2.7-1]+[1.9-1]=0.35)$. Osteoclast activation therefore represents between 35 and $100 \%$ of the total effect of PTH. These results are consistent with the conclusion obtained from the quantitation of TRAP-positive, multinucleated cells that most of the stimulation of resorption induced by PTH or IL-6 likely reflects osteoclast activation rather than osteoclast differentiation. However, we cannot exclude the possibility that PTH or IL-6 induces the final step(s) of differentiation; that is, inactive, TRAP-positive, multinucleated cells might be induced to begin to resorb bone. Nonetheless, such an effect would be clearly distinct from the well-documented ability of IL-6 to induce formation of TRAP-positive, multinucleated cells from mononuclear precursors (38-40).

\section{Discussion}

In this study, we show that osteoblastic adenyl cyclase activation is required for stimulation of osteoclast activity by PTH in cultures containing osteoclasts from rat long bones and UMR106-01 rat osteoblast-like osteosarcoma cells. These results, taken together with our previous demonstration that activation of adenyl cyclase by PTH is also required for induction of IL- 6 by osteoblasts, ${ }^{2}$ led us to examine whether IL- 6 is one of the crucial cytokines produced by osteoblasts to stimulate bone resorption. We found that moderate stimulation of osteoclast resorptive activity by PTH is dependent on IL-6 production. Interestingly, this dependence on IL-6 can be overcome by strong stimulation of resorption by PTH.

PTH-(3-34) stimulates phospholipase $\mathrm{C}$ activity without affecting adenyl cyclase (31). As this partial agonist has little if any effect on osteoclast activity in our cultures, osteoblast adenyl cyclase is involved in stimulation of bone resorption by PTH. Similarly, PTH-(1-34) is $100-1,000$-fold more potent at inducing resorption in organ culture assays than is PTH-(334) (30). Moreover, Rp-cAMPS, a specific inhibitor of protein kinase A, blocks PTH-induced resorption in both organ cultures and osteoblast/osteoclast cocultures without affecting resorption induced by 1,25 -dihydroxyvitamin $\mathrm{D}_{3}(41,42)$. However, these results do not exclude a role for the phospholipase $C$ pathways in PTH-induced bone resorption. Nonetheless, they indicate that if such pathways are involved, they act together with the adenyl cyclase pathway. In support of this concept, activation of adenyl cyclase by PTH is linked to bone resorption in a rodent model of renal osteodystrophy (43). In contrast, organ culture studies have shown that adenyl cyclase inhibitors are unable to block stimulation of resorption by PTH (44). However, in these organ cultures, the inhibitors may be acting, at least in part, on cells other than osteoblasts. For example, since stimulation of osteoclast cAMP inhibits resorption $(28$, 
$45,46)$, direct action of the inhibitors on osteoclasts might obscure any reduction of osteoblast action. Therefore, we and others (30) have taken advantage of the specific targeting of both PTH-(1-34) and PTH-(3-34) to osteoblasts to demonstrate that the adenyl cyclase signal transduction system in these cells is involved in PTH-induced bone resorption.

Moderate (two- to threefold) stimulation of resorption by PTH is blocked by an antibody directed against the IL- 6 receptor. As our assay likely reflects primarily activation of mature osteoclasts rather than induction of osteoclast differentiation, the present study is the first to identify a cytokine that is required for stimulation of osteoclast activity in response to PTH. In contrast, macrophage-colony stimulating factor is required for PTH-induced stimulation of osteoclast differentiation but not of osteoclast activity (47). Dependence on cytokines, like IL6 , that are rapidly induced (5) provides a mechanism to explain how a brief exposure to PTH stimulates bone resorption for a prolonged period of time (48). The dependence on IL- 6 when the stimulation due to PTH is moderate is likely caused by induction of synergistic cytokines by PTH. Blockage of IL-6 activity would then inhibit PTH-dependent resorption. In contrast, when PTH strongly stimulates resorption, levels of the other cytokines are adequate to compensate for addition of the IL-6 receptor antibody and IL-6 dependence is overcome. Likely candidates for these alternatively synergistic and redundant cytokines include other members of the IL- 6 family, such as LIF and IL-11, which also stimulate bone resorption (49$52)$ and are produced by osteoblasts in response to PTH $(5,11$, $52,53) .^{2}$ IL-6, IL-11, and LIF have similar effects on cells since their receptors share subunits responsible for signal transduction (54). Such synergism and redundancy is a characteristic of many cytokines. An example that is particularly relevant to this study is synergistic stimulation of bone resorption by low concentrations of IL-6, LIF, and IL-1 $(9,51)$. A similar effect may also occur in mice in which the IL- 6 gene has been ablated by homologous recombination; that is, the accelerated resorption that has recently been reported in these mice (55) might be due to chronic upregulation of other, redundant, cytokines that stimulate resorption.

In contrast to our results, it has been reported that a neutralizing antibody directed against IL-6 does not affect osteoclast differentiation induced in organ cultures by PTH (19). There are several possible explanations for the lack of effect of the antibody in that study. These include the possible lack of access of the antibody to the critical cellular milieu inside the organ cultures, whereas our cell cultures allow rapid access. Alternatively, the observed results in that study may be due to measurement of osteoclast differentiation rather than osteoclast activity, investigation of cells at different developmental stages ( see Introduction), or use of antibodies with different affinities or avidities.

Addition of exogenous IL- 6 to our cultures also stimulates bone resorption, which similar to that stimulated by PTH likely reflects osteoclast activation. Although relatively high levels of IL-6 were required, lower levels are likely to be effective in the presence of other synergistic cytokines (see previous paragraphs). This stimulation of osteoclast activity would be complementary to the previously described stimulation of osteoclast differentiation $(2,7,37)$.

Our results do not allow assignment of the cell type that directly responds to IL- 6 during resorption induced by either PTH or by exogenous IL-6. Although IL-6 receptors are found on other monocyte lineage cells (56), it is unknown whether osteoclasts express IL-6 receptors. IL-6 stimulates bone resorption by osteoclast-like cells obtained from giant cell tumors and these cells express immunohistochemically detectable IL6 receptors (57). However, there are considerable differences between cell surface proteins expressed by osteoclasts and those expressed by the tumor cells $(58,59)$. In fact, it has been reported that IL- 6 does not stimulate resorption by highly purified osteoclasts (60). In contrast, osteoblasts contain IL-6 receptor mRNA (10). Moreover, our study provides functional evidence for existence of IL- 6 receptors on osteoblasts as we showed that IL-6 stimulates expression of IL-6 and LIF mRNAs by MC3T3-E1 osteoblasts. Similar results were also obtained with UMR106-01 osteoblast-like cells (our unpublished data). IL-6 has also been shown to upregulate expression by osteoblasts of monocyte chemoattractant protein-1 $(61,62)$. IL-6 may therefore regulate resorption indirectly, like many other agents, by altering production of as yet unidentified osteoblastderived cytokines. In this case, IL- 6 would function in an autocrine fashion to mediate stimulation of osteoclast activity by PTH.

In summary, induction by PTH of osteoclast activity is dependent on activation of the adenyl cyclase signal transduction pathway in osteoblasts. Since we had shown previously that adenyl cyclase is also required for stimulation of IL-6 expression, we examined whether IL-6 is involved in stimulation of osteoclast activity. We found that addition of exogenous IL-6 stimulates resorption. Moreover, moderate stimulation of osteoclast activity by PTH in these cultures requires IL-6. The IL-6 dependence is overcome when PTH strongly stimulates resorption, probably because multiple, redundant cytokines are produced that compensate for the absence of IL- 6 activity. Since many resorptive agents in addition to PTH induce IL-6, our results suggest that this cytokine might be involved in stimulation of resorption by these agents as well.

\section{Acknowledgments}

We are grateful to R. Tracy Ballock, Cathleen Carlin, and Sharon Stevenson for many helpful discussions; Tom Hornick and Mas Sato for advice on isolating osteoclasts; Jim Toth and Danzhu Guo for help with histomorphometry; Miguel Khoury, Jim Ninomiya, and Ajay Vaidya for help with cell isolations; and Clayton van Doren and Paul Jones for statistical advice.

This work was supported in part by the Arthritis Foundation (postdoctoral fellowship to E. M. Greenfield), the John A. Hartford Foundation (Geriatric Medicine Summer Student Fellowship to S. M. Shaw), the Ray A. and Robert L. Kroc Foundation (Summer Research Fellowship to S. M. Shaw), the Fred A. and Alice Lennon Fellowship (M. A. Banks), the Orthopaedic Research and Education Foundation (research grant 91-010 to E. M. Greenfield, and Resident Research Fellowship 93-029 to M. A. Banks), and the National Institutes of Health (AR41674 to E. M. Greenfield).

\section{References}

1. Rodan, G. A., and T. J. Martin. 1981. Role of osteoblasts in hormonal control of bone resorption: a hypothesis. Calcif. Tissue Int. 33:349-351.

2. Horowitz, M. C. 1993. Cytokines and estrogen in bone: anti-osteoporotic effects. Science (Wash. DC). 260:626-627.

3. McSheehy, P. M. J., and T. J. Chambers. 1986. Osteoblast-like cells in the presence of parathyroid hormone release a soluble factor that stimulates osteoclastic bone resorption. Endocrinology. 119:1654-1659.

4. Evely, R. S., A. Bonomo, H.-G. Schneider, J. M. Moseley, J. Gallagher, and T. J. Martin. 1991. Structural requirements for the action of parathyroid 
hormone-related protein (PTHrP) on bone resorption by isolated osteoclasts. $J$. Bone Miner. Res. 6:85-93.

5. Greenfield, E. M., S. A. Gornik, M. C. Horowitz, H. J. Donahue, and S. M. Shaw. 1993. Regulation of cytokine expression in osteoblasts by parathyroid hormone: rapid stimulation of interleukin- 6 and leukemia inhibitory factor mRNA. J. Bone Miner. Res. 8:1163-1171.

6. Feyen, J. H. M., P. Elford, F. E. D. Padova, and U. Trechsel. 1989. Interleukin- 6 is produced by bone and modulated by parathyroid hormone. J. Bone Miner Res. 4:633-638.

7. Lowik, C., G. van der Pluijm, H. Bloys, K. Hoekman, O. Bijvoet, L. Aarden, and S. Papapoulos. 1989. Parathyroid hormone and PTH-like protein stimulate interleukin- 6 production by osteogenic cells: a possible role of interleukin-6 in osteoclastogenesis. Biochem. Biophys. Res. Commun. 162:1546-1552.

8. Horowitz, M., M. Brown, K. Insogna, D. Coleman, M. Centrella, J. Phillips and E. Weir. 1990. PTHrP and PTH induce the secretion of IL-6 by a clonal osteosarcoma cell line. In Molecular and Cellular Biology of Cytokines. J. J. Oppenheims, editor. Wiley-Liss, New York. 471-476.

9. Ishimi, Y., C. Miyaura, C. H. Jin, T. Akatsu, E. Abe, Y. Nakamura, A Yamaguchi, S. Yoshiki, T. Matsuda, T. Hirano, T. Kishimoto, and T. Suda 1990. IL-6 is produced by osteoblasts and induces bone resorption. J. Immunol. 145:3297-3303.

10. Littlewood, A. J., J. Russell, G. R. Harvey, D. E. Hughes, R. G. G. Russell and M. Gowen. 1991. The modulation of the expression of IL-6 and its receptor in human osteoblasts in vitro. Endocrinology. 129:1513-1520.

11. Franchimont, N., Y. Vrindts, S. Gaspar, M. Lopez, R. Gathy, D. d. Groote J. Y. Reginster, and P. Franchimont. 1993. Parathyroid hormone (1-34) stimulates and $1,25(\mathrm{OH})_{2}$ vitamin $\mathrm{D}_{3}$ inhibits leukemia inhibitory factor (LIF) production by osteoblasts in vitro. In Fourth International Symposium on Osteoporosis. C. Christiansen and B. Riiss, editors. Handelstrykkeriet Aalborg ApS, Aalborg. 249250.

12. Linkhart, T. A., S. G. Linkhart, D. C. MacCharles, D. L. Long, and D. D. Strong. 1991. Interleukin-6 messenger RNA expression and interleukin-6 protein secretion in cells isolated from normal human bone: regulation by interleukin-1. J. Bone Miner. Res. 6:1285-1294.

13. Chaudhary, L. R., T. C. Spelsberg, and B. L. Riggs. 1992. Production of various cytokines by normal human osteoblast-like cells in response to interleukin$1 \beta$ and tumor necrosis factor- $\alpha$ : lack of regulation by $17 \beta$-estradiol. Endocrinol ogy. 130:2528-2534.

14. Girasole, G., R. L. Jilka G. Passeri, S. Boswell, G. Boder, D. C. Williams, and S. C. Manologas. 1992. 17 $\beta$-estradiol inhibits interleukin-6 production by bone marrow-derived stromal cells and osteoblasts in vitro. J. Clin. Invest. 89:883-891.

15. Horowitz, M., J. Phillips, and M. Centrella. 1992. TGF $\beta$ regulates IL-6 secretion by osteoblasts. In Calcium Regulating Hormones and Bone Metabolism. D. V. Cohn, C. Gennari, and A. H. Tashjians, editors. Elsevier, Amsterdam. 275 280.

16. Lacey, D. L., L. E. Groso, S. A. Moser, J. Erdmann, H.-L. Tan, R. Pacifici, and D. T. Villareal. 1993. IL-1-induced murine osteoblast IL-6 production is mediated by the type $1 \mathrm{IL}-1$ receptor and is increased by 1,25 dihydroxyvitamin $D_{3}$. J. Clin. Invest. 91:1731-1742.

17. Barton, B. E., and R. Mayer. 1989. IL-3 induces differentiation of bone marrow precursor cells to osteoclast-like cells. J. Immunol. 143:3211-3216.

18. Al-Humidan, A., S. H. Ralston, D. E. Hughes, K. Chapman, L. Aarden, R. G. G. Russell, and M. Gowen. 1991. Interleukin-6 does not stimulate bone resorption in neonatal mouse calvariae. J. Bone Miner. Res. 6:3-7.

19. Holt, I., M. W. J. Davie, I. P. Braidman, and M. J. Marshall. 1994 Interleukin- 6 does not mediate the stimulation by prostaglandin $E_{2}$, parathyroid hormone, or 1,25 dihydroxyvitamin $D_{3}$ of osteoclast differentiation and bone resorption in neonatal mouse parietal bones. Calcif. Tissue Int. 55:114-119.

20. Jilka, R. L., G. Hangoc, G. Girasole, G. Passeri, D. C. Williams, J. S Abrams, B. Boyce, H. Broxmeyer, and S. C. Manolagas. 1992. Increased osteoclast development after estrogen loss: mediation by interleukin-6. Science (Wash DC). $257: 88-91$

21. Passeri, G., G. Girasole, R. L. Jilka, and S. C. Manolagas. 1993. Increased interleukin-6 production by murine bone marrow and bone cells after estrogen withdrawal. Endocrinology. 133:822-828.

22. Roodman, G. D., N. Kurihara, Y. Ohsaki, A. Kukita, D. Hosking, A. Demulder, J. F. Smith, and F. R. Singer. 1992. Interleukin 6: a potential autocrine/ paracrine factor in Paget's disease of bone. J. Clin. Invest. 89:46-52.

23. Hoyland, J. A., A. J. Freemont, and P. T. Sharpe. 1994. Interleukin-6, II6 receptor, and IL-6 nuclear factor gene expression in Paget's disease. J. Bone Miner. Res. 9:75-80.

24. Devlin, R. D., H. G. Bone, and G. D. Roodman. 1994. Stimulation of osteoclast-like multinucleated cell function in long-term human bone marrow cultures by the serum of patients with Gorham-Stout or disappearing bone disease. J. Bone Miner. Res. 9:S1:140

25. Yoneda, T., M. Nakai, K. Moriyama, L. Scott, N. Ida, T. Kunitomo, and G. R. Mundy. 1993. Neutralizing antibodies to human interleukin 6 reverse hypercalcemia associated with a human squamous carcinoma. Cancer Res. 53:737-740
26. Abou-Samra, A.-B., H. Juppner, T. Force, M. W. Freeman, Z.-F. Kong, E. Schipani, P. Urena, J. Richards, J. V. Bonventre, J. T. Potts, et al. 1992. Expression cloning of a common receptor for parathyroid hormone and parathyroid hormone-related peptide from rat osteoblast-like cells: a single receptor stimulates intracellular accumulation of both cAMP and inositol trisphosphates and increases intracellular free calcium. Proc. Natl. Acad. Sci. USA. 89:2732-2736.

27. Lorenzo, J. A., and L. G. Raisz. 1981. Divalent cation ionophores stimulate resorption and inhibit DNA synthesis in cultures fetal rat bone. Science (Wash. DC). 212:1157-1159.

28. Klein, D. C., and L. G. Raisz. 1971. Role of adenosine-3'-5'-monophosphate in the hormonal regulation of bone resorption: studies with cultured fetal bone. Endocrinology. 89:818-826.

29. Abraham, D. C., C. L. Wadkins, and H. H. Conaway. 1988. Enhancement of fetal rat limb resorption by phorbol ester (PMA) and ionophore A-23187. Calcif. Tissue Int. 42:191-195.

30. Herrmann-Erlee, M. P. M., P. J. Nijweide, J. M. v. d. Meer, and M. A. C. Ooms. 1983. Action of bPTH and bPTH fragments on embryonic bone in vitro: dissociation of the cyclic AMP and bone resorbing response. Calcif. Tissue Int. 35:70-77.

31. Fujimori, A., S. L. Cheng, L. V. Avioli, and R. Civitelli. 1991. Dissociation of second messenger activation by parathyroid hormone fragments in osteosarcoma cells. Endocrinology. 128:3032-3039.

32. Makino, R., T. Sekiya, and K. Hayashi. 1990. Evaluation of quantitative detection of mRNA by the reverse transcription-polymerase chain reaction. Technique (Phila.). 2:295-301.

33. Partridge, N. C., D. Alcorn, V. P. Michelangeli, G. Ryan, and T. J. Martin. 1983. Morphological and biochemical characterization of four clonal osteogenic sarcoma cell lines of rat origin. Cancer Res. 43:4308-4314.

34. Berthois, Y., J. A. Katzenellenbogen, and B. S. Katzenellenbogen. 1986. Phenol red in tissue culture media is a weak estrogen: implications concerning the study of estrogen-responsive cells in culture. Proc. Natl. Acad. Sci. USA. 83:2496-2500.

35. Sato, M., and W. Grasser. 1990. Effects of bisphosphonates on isolated rat osteoclasts as examined by reflected light microscopy. J. Bone Miner. Res. $5: 31-38$.

36. Sahni, M., H. L. Guenther, H. Fleisch, P. Collin, and T. J. Martin. 1993. Bisphosphonates act on bone resorption through the mediation of osteoblasts. $J$. Clin. Invest. 91:2004-2011.

37. Roodman, G. 1992. Interleukin-6: an osteotropic factor? J. Bone Miner. Res. 7:475-478.

38. Kurihara, N., D. Bertolini, T. Suda, Y. Akiyama, and G. D. Roodman. 1990. IL-6 stimulates osteoclast-like multinucleated cell formation in long term human marrow cultures by inducing IL-1 release. J. Immunol. 144:4226-4230.

39. Amano, S., S. Hanazawa, Y. Kawata, K. Ohta, H. Kitami, and S. Kitano. 1992. An assay system utilizing devitalized bone for assessment of differentiation of osteoclast progenitors. J. Bone Miner. Res. 7:321-328.

40. Tamura, T., N. Udagawa, N. Takahashi, C. Miyaura, S. Tanaka, Y. Yamada, Y. Koishihara, Y. Ohsugi, K. Kumaki, T. Taga, et al. 1993. Soluble interleukin-6 receptor triggers osteoclast formation by interleukin-6. Proc. Natl. Acad. Sci. USA. 90:11924-11928.

41. Kaji, H., T. Sugimoto, M. Kanatani, and M. Fukase. 1992. The activation of cAMP-dependent protein kinase is directly linked to the stimulation of bone resorption by parathyroid hormone. Biochem. Biophys. Res. Commun. 182:13561361.

42. Ljunggren, O., and S. Ljunghall. 1993. The cyclic-AMP antagonist adenosine-3',5'-cyclic monophosphosphorothioate, RP-isomer inhibits parathyroid hormone induced bone resorption, in vitro. Biochem. Biophys. Res. Commun. 193:821-826.

43. Jablonski, G., C. C. Danielsen, L. Mosekilde, and J. O. Gordeladze. 1994. Surgically induced uremia in rats II: osseous PTH-susceptible signaling systems as predictors of bone resorption. Calcif. Tissue Int. 55:281-287.

44. Reid, I. R., C. Lowe, J. Cornish, D. H. Gray, and S. J. M. Skinner. 1990. Adenylate cyclase blockers dissociate PTH-stimulated bone resorption from cAMP production. Am. J. Physiol. 258:E708-E714.

45. Chambers, T. J., P. M. J. McSheehy, B. M. Thomson, and K. Fuller. 1985. The effect of calcium-regulating hormones and prostaglandins on bone resorption by osteoclasts disaggregated from neonatal rabbit bones. Endocrinology. 60:234239.

46. Murrills, R. J., and D. W. Dempster. 1990. The effects of stimulators of intracellular cyclic AMP on rat and chick osteoclasts in vitro: validation of a simplified light microscope assay of bone resorption. Bone (Tarrytown). 11:333344.

47. Weir, E., I. Paliwal, K. Insogna, and C. Lowik. 1994. Colony stimulating factor-1 regulates osteoclast formation and function in PTH-induced bone resorption. J. Bone Miner. Res. 9:S1:310.

48. Raisz, L. G., C. L. Trummel, and H. Simmons. 1972. Induction of bone resorption in tissue culture. Prolonged response after brief exposure to parathyroid hormone or 25-hydroxycholecalciferol. Endocrinology. 90:744-751.

49. Abe, E., Y. Ishimi, N. Takahashi, T. Akatsu, H. Ozawa, H. Yamana, S. Yoshiki, and T. Suda. 1988. A differentiation-inducing factor produced by the 
osteoblastic cell line MC3T3-E1 stimulates bone resorption by promoting osteoclast formation. J. Bone Miner. Res. 3:635-645.

50. Reid, I. R., C. Lowe, J. Cornish, S. J. M. Skinner, D. J. Hilton, T. A. Wilson, D. P. Gearing, and T. J. Martin. 1990. Leukemia inhibitory factor: a novel bone-active cytokine. Endocrinology. 126:1416-1420.

51. Ishimi, Y., E. Abe, C. H. Jin, C. Miyaura, M. H. Hong, M. Oshida, H. Kurosawa, Y. Yamaguchi, M. Tomida, M. Hozumi, and T. Suda. 1992. Leukemia inhibitory factor/differentiation-stimulating factor (LIF/D-factor): regulation of its production and possible roles in bone metabolism. J. Cell. Physiol. 152:7178.

52. Girasole, G., G. Passeri, R. L. Jilka, and S. C. Manolagas. 1994. Interleukin-11: a new cytokine critical for osteoclast development. J. Clin. Invest. 93:1516-1524.

53. Elias, J. A., W. Tang, and M. C. Horowitz. 1995. Cytokine and hormonal stimulation of human osteosarcoma interleukin-11 production. Endocrinology. 136:489-498.

54. Kishimoto, T., T. Taga, and S. Akira. 1994. Cytokine signal transduction. Cell. 76:253-262.

55. Poli, V., R. Balena, E. Fattori, A. Markatos, M. Yamamoto, H. Tanaka G. Ciliberto, G. A. Rodan, and F. Costantini. 1994. Interleukin-6 deficient mice are protected from bone loss caused by estrogen depletion. EMBO (Eur. Mol. Biol. Organ.) J. 13:1189-1196.
56. Taga, T., Y. Kawanishi, R. R. Hardy, T. Hirano, and T. Kishimoto. 1987. Receptors for B cell stimulatory factor 2. J. Exp. Med. 166:967-981.

57. Ohsaki, Y., S. Takahashi, T. Scarez, A. Demulder, T. Nishihara, R. Williams, and G. D. Roodman 1992. Evidence for an autocrine/paracrine role for interleukin-6 in bone resorption by giant cells from giant cell tumors of bone. Endocrinology. 131:2229-2234.

58. Athanasou, N. A., J. Quinn, and J. O. McGee. 1988. Immunocytochemical analysis of the human osteoclast: phenotypic relationship to other marrow-derived cells. Bone Miner. 3:317-333.

59. Clohisy, D. R., L. Vorlicky, T. R. Oegema, D. Snover, and R. C. Thompson. 1993. Histochemical and immunohistochemical characterization of cells constituting the giant cell tumor of bone. Clin. Orthop. Rel. Res. 287:259-265.

60. Hattersley, G., E. Dorey, M. A. Horton, and T. J. Chambers. 1988. Human macrophage colony-stimulating factor inhibits bone resorption by osteoclasts disaggregated from rat bone. J. Cell. Physiol. 137:199-203.

61. Ohmori, Y., and T. A. Hamilton. 1994. Cell type and stimulus specific regulation of chemokine gene expression. Biochem. Biophys. Res. Commun. 198:590-596.

62. Zhu, J. F., A. J. Valente, J. A. Lorenzo, D. Carnes, and D. T. Graves. 1994. Expression of monocyte chemoattractant protein 1 in human osteoblastic cells stimulated by proinflammatory mediators. J. Bone Miner. Res. 9:1123-1130. 